\title{
Experimental Identification of Thermophysical Properties in Heterogeneous Materials with Integral Transformation of Temperature Measurements from Infrared Thermography
}

Diego C. Knupp , Carolina P. Naveira-Cotta , Helcio R. B. Orlande \& Renato M. Cotta

To cite this article: Diego C. Knupp , Carolina P. Naveira-Cotta, Helcio R. B. Orlande \& Renato M. Cotta (2013) Experimental Identification of Thermophysical Properties in Heterogeneous Materials with Integral Transformation of Temperature Measurements from Infrared Thermography, Experimental Heat Transfer, 26:1, 1-25, DOI: 10.1080/08916152.2011.631079

To link to this article: https://doi.org/10.1080/08916152.2011.631079

曲 Published online: 16 Jan 2013.

Submit your article to this journal $₫$

Џ Article views: 187

Citing articles: 5 View citing articles $₫$ 


\title{
EXPERIMENTAL IDENTIFICATION OF THERMOPHYSICAL PROPERTIES IN HETEROGENEOUS MATERIALS WITH INTEGRAL TRANSFORMATION OF TEMPERATURE MEASUREMENTS FROM INFRARED THERMOGRAPHY
}

\author{
Diego C. Knupp, ${ }^{1}$ Carolina P. Naveira-Cotta, ${ }^{1}$ \\ Helcio R. B. Orlande, ${ }^{1}$ and Renato M. Cotta ${ }^{1}$ \\ ${ }^{1}$ Laboratory of Transmission and Technology of Heat (LTTC), \\ Mechanical Engineering Department - POLI and COPPE, \\ Universidade Federal do Rio de Janeiro (UFRJ), Rio de Janeiro, Brazil
}

This work deals with the experimental estimation of spatially variable thermal conductivity and diffusivity in heterogeneous media, with temperature measurements obtained via infrared thermography being used in the inverse analysis. The direct problem solution for a one-dimensional heat conduction experiment is analytically obtained via integral transforms, and the related eigenvalue problem is solved by the generalized integral transform technique. The inverse problem is handled by Bayesian inference through a Markov chain Monte Carlo algorithm. The functional representation and estimation is based on the eigenfunction expansion of the thermal conductivity and diffusivity themselves, and the unknown parameters become the corresponding expansion coefficients. The inverse analysis is performed on the transformed experimental temperature field instead of employing the actual local temperature measurements, thus promoting a significant data reduction through the integral transformation of the experimental measurements. A demonstration experiment is built involving partially heated thin plates made of bakelite and polystyrene, including a variable thickness plate to simulate spatially variable thermophysical properties.

Keywords heterogeneous media, inverse problem, Bayesian inference, Markov chain Monte Carlo method, integral transforms, infrared thermography

\section{INTRODUCTION}

Heat conduction problems defined in heterogeneous media involve space variations of the physical properties in different forms, depending on the type of heterogeneity that prevails, such as large-scale variations in functionally graded materials (FGMs), abrupt variations in laminated media, and random variations due to fluctuations of local concentrations in dispersed systems [1-5]. The accurate determination of local variations in physical properties within heterogeneous media requires an experimental technique

Received 26 August 2011; accepted 13 September 2011.

Address correspondence to Prof. Renato M. Cotta, Mechanical Engineering Department, PEM/COPPE - UFRJ - Cx. Postal 68503, Cidade Universitária, Rio de Janeiro, 21945-970 Brazil. E-mail: cotta@ mecanica. coppe.ufrj.br 


\begin{tabular}{|c|c|c|c|}
\hline \multicolumn{4}{|c|}{ NOMENCLATURE } \\
\hline$c_{p}(x)$ & $\begin{array}{l}\text { space variable specific heat } \\
\left(\mathrm{J} / \mathrm{kg}^{\circ} \mathrm{C}\right) \text {, Eq. }(1 \mathrm{e})\end{array}$ & $q_{w}(x)$ & $\begin{array}{l}\text { applied heat flux spatial distribution } \\
\left(\mathrm{W} / \mathrm{m}^{2}\right)\end{array}$ \\
\hline \multirow[t]{2}{*}{$d(x)$} & linear dissipation operator & $t$ & time variable $(\mathrm{sec})$ \\
\hline & coefficient, Eq. (1a) & $T_{m}(x, t)$ & thickness averaged temperature \\
\hline \multirow{2}{*}{$h_{e f f}(x)$} & effective heat transfer coefficient & & distribution $\left({ }^{\circ} \mathrm{C}\right)$ \\
\hline & $\left(\mathrm{W} / \mathrm{m}^{2 \circ} \mathrm{C}\right)$, Eq. (1f) & $T_{\infty}$ & temperature of surrounding air $\left({ }^{\circ} \mathrm{C}\right)$ \\
\hline \multirow[t]{2}{*}{$k(x)$} & space variable thermal & $w(x)$ & thermal capacity $\left(\mathrm{J} / \mathrm{m}^{3 \circ} \mathrm{C}\right)$, Eq. (1a) \\
\hline & conductivity (W/mº C), Eq. (1a) & $x$ & space coordinate \\
\hline$L_{x}$ & plate length (m) & $\mathbf{Y}$ & vector of measurements \\
\hline$L_{z}$ & plate thickness (m) & & \\
\hline \multirow[t]{2}{*}{$N$} & truncation order in temperature & \multicolumn{2}{|c|}{ Greek Letters } \\
\hline & expansion & $\mu$ & eigenvalues of the direct problem \\
\hline$N_{i}$ & $\begin{array}{l}\text { normalization integrals in } \\
\text { eigenvalue problem }\end{array}$ & $\rho(x)$ & $\begin{array}{l}\text { space variable density }\left(\mathrm{kg} / \mathrm{m}^{3}\right) \text {, } \\
\text { Eq. }(1 \mathrm{e})\end{array}$ \\
\hline$N_{P}$ & $\begin{array}{l}\text { number of parameters to be } \\
\text { estimated, Eq. ( } 8 \text { a) }\end{array}$ & $\psi$ & eigenfunctions of the direct problem \\
\hline \multirow[t]{3}{*}{$N_{w}, N_{k}, N_{d}$} & truncation orders in coefficients & \multicolumn{2}{|c|}{ Subscripts and Superscripts } \\
\hline & expansions, $w(x), k(x)$ & - & integral transform \\
\hline & and $d(x)$, respectively & $\sim$ & normalized eigenfunction \\
\hline $\mathbf{P}$ & vector of unknown parameters & $f$ & filtering function in coefficients \\
\hline$P(x, t)$ & source term, Eq. (1a) & & expansion \\
\hline$q(x, t)$ & $\begin{array}{l}\text { applied heat flux }\left(\mathrm{W} / \mathrm{m}^{2}\right) \text {, } \\
\text { Eq. }(1 \mathrm{~g})\end{array}$ & $i$ & order of eigenquantities \\
\hline
\end{tabular}

that provides abundant information on spatially distributed measurements in order to provide a firm basis for application of the appropriate inverse analysis. In addition, as the morphology of the medium directly influences the spatial behavior of the physical properties, it becomes critical not to disturb the structure along the experimental campaign by introducing intrusive sensors, such as thermocouples in the case of temperature measurements. Therefore, aimed at the identification of spatially variable thermophysical properties, the adoption of the non intrusive technique of infrared thermography becomes of major interest, providing a large volume of measurements, both in space and time, and offering new perspectives towards the analysis of heat conduction in heterogeneous media $[6,7]$.

The present work thus provides an experimental demonstration of a recently proposed inverse analysis methodology $[8,9]$ that combines the integral transform method for the direct problem and Bayesian inference for the inverse problem solution, here incorporating infrared thermography for the experimental data acquisition. Bayesian inference [10-13] has been demonstrated to be a powerful tool in the estimation of spatially variable equation and boundary condition coefficients in heat diffusion problems by employing the Markov chain Monte Carlo (MCMC) method, with the MetropolisHastings algorithm being employed for the sampling procedure [8, 9]. This sampling procedure used to recover the posterior distribution is, in general, the most expensive computational task, since the direct problem is calculated for each state of the Markov chain. In this context, the use of a fast, accurate, and robust computational implementation of the direct solution is extremely important. Thus, the integral transformation method 
[14-19] becomes very attractive for combined use with the MCMC method. Such is the case, because analytical expressions can be obtained for different quantities required in the implementation, thus avoiding repetitive numerical tasks [19]. Also, instead of seeking the function estimation in the form of a sequence of local values for the variable coefficients, an alternative path is utilized based on the eigenfunction expansion of the coefficients to be estimated themselves [19]. Another important aspect of this combined methodology is the analysis of the inverse problem in the transformed temperature field, instead of employing the directly measured temperature data along the domain. Thus, the experimental spatially distributed temperature values at each time are first integral transformed to yield transformed temperature values of increasing order. This procedure is particularly advantageous when a substantial amount of experimental measurements are available, such as with the infrared thermography technique employed here, permitting a remarkable data reduction.

In order to demonstrate the applicability of the proposed thermophysical properties estimation approach, an experiment was built and tested [20, 21], which employs samples made of thermally thin plates partially heated with an electrical resistance on one surface, while the other surface is exposed to the infrared thermography system. As the first verification experiment, homogeneous bakelite plates are used in order to demonstrate that the methodology presented in this work is able to recover the homogeneous thermophysical properties without the assumption or previous knowledge of a uniform functional behavior. In a second verification experiment, polystyrene plates manufactured with controlled thickness varying almost linearly along the plates' length are used. This case allows for modeling the space-varying thickness as space-varying effective thermophysical properties, which are then estimated using the present methodology. An infrared camera (FLIR SC660, FLIR Systems, Inc., USA) is used to provide a fairly large number of temperature measurements over the plate's surface along time, and a combination of uniform and Gaussian priors are employed in the MCMC algorithm.

\section{DIRECT PROBLEM SOLUTION}

A one-dimensional special case of the general formulation on transient heat conduction presented in [19] is considered, for the transversally averaged temperature field within a thermally thin plate, $T_{m}(x, t)$, in the region $x \in\left[0, L_{x}\right]$. The formulation includes the space-variable thermal conductivity and heat capacity, as shown in Eqs. (1a)-(1g). The equation coefficients $\rho(x), c_{p}(x)$, and $k(x)$ are thus responsible for the information related to the heterogeneity of the medium. The heat conduction equation with initial and boundary conditions are given by

$$
\begin{aligned}
w(x) \frac{\partial T_{m}(x, t)}{\partial t}= & \frac{\partial}{\partial x}\left(k(x) \frac{\partial T_{m}(x, t)}{\partial x}\right) \\
& -d(x) T_{m}(x, t)+P(x, t), \quad 0<x<L_{x}, \quad t>0 \\
T_{m}(x, 0)= & T_{\infty}
\end{aligned}
$$




$$
\begin{gathered}
\left.\frac{\partial T_{m}(x, t)}{\partial x}\right|_{x=0}=0, \quad t>0 ; \\
\left.\frac{\partial T_{m}(x, t)}{\partial x}\right|_{x=L_{x}}=0, \quad t>0 ;
\end{gathered}
$$

where

$$
\begin{aligned}
w(x) & =\rho(x) c_{p}(x), \\
d(x) & =\frac{h_{e f f}(x)}{L_{z}} \\
P(x, t) & =\frac{q(x, t)}{L_{z}}-\frac{h_{e f f}(x)}{L_{z}} T_{\infty} .
\end{aligned}
$$

Equations (1) model a typical one-dimensional transient thermal conductivity experimental set-up for a thermally thin plate, including prescribed heat flux at one surface and convective and radiative heat losses at the opposite surface (see Figure 1), and based

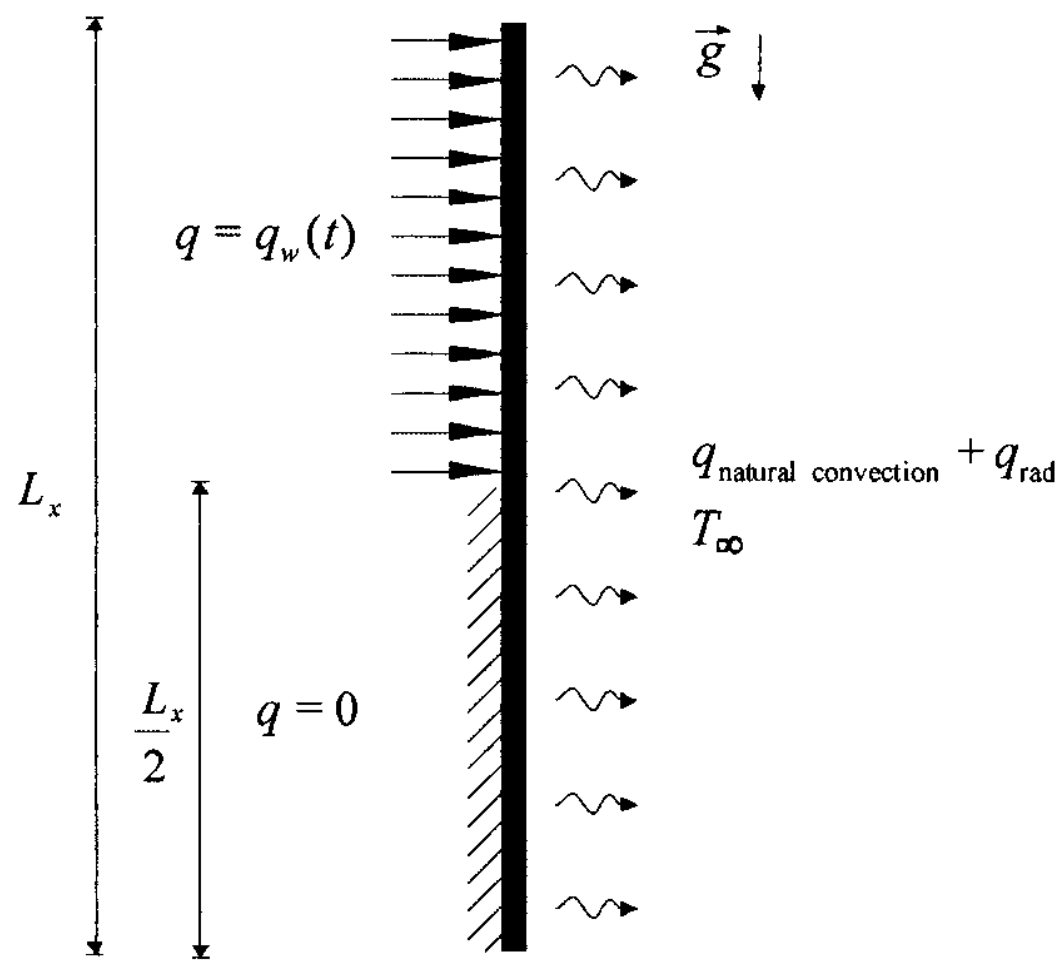

Figure 1. Schematic representation of the experimental set-up for thermophysical properties identification in heterogeneous media. 
on a lumped formulation across the sample thickness. The exposed surface allows for temperature measurements acquisition via infrared thermography [20, 21].

In the second verification experiment presented in this work, the sample plate thickness varies with $x$. In such a case, the problem coefficients are given by

$$
\begin{aligned}
w(x) & =\hat{w}(x) \cdot L_{z}(x), \\
k(x) & =\hat{k}(x) \cdot L_{z}(x), \\
h_{e f f}(x) & =\hat{h}_{e f f}(x) / n_{z}(x),
\end{aligned}
$$

where $\hat{w}(x), \hat{k}(x)$, and $\hat{h}_{e f}(x)$ are the actual properties and heat transfer coefficient; $L_{z}(x)$ is the spatially variable thickness; and $n_{z}(x)$ is the direction cosine.

The formal exact solution of Eqs. (1) is then obtained with the classical integral transform method [19] and is written as

$$
T_{m}(x, t)=T_{\infty}+\sum_{i=1}^{\infty} \tilde{\psi}_{i}(x) \int_{0}^{t} \bar{g}_{i}\left(t^{\prime}\right) e^{-\mu_{i}^{2}\left(t-t^{\prime}\right)} d t^{\prime},
$$

where the eigenvalues $\mu_{i}$ and eigenfunctions $\psi_{i}(x)$ are obtained from the eigenvalue problem that contains the information about the heterogeneous medium, in the following form:

$$
\frac{d}{d x}\left[k(x) \frac{d \psi_{i}(x)}{d x}\right]+\left(\mu_{i}^{2} w(x)-d(x)\right) \psi_{i}(x)=0, \quad x \in\left[0, L_{x}\right],
$$

with boundary conditions

$$
\begin{array}{ll}
\frac{d \psi_{i}(x)}{d x}=0, & x=0, \\
\frac{d \psi_{i}(x)}{d x}=0, & x=L_{x} .
\end{array}
$$

Also, the other quantities that appear in the exact solution of Eq. (3) are computed after solving Eqs. (4), such as

$$
\begin{aligned}
\tilde{\psi}_{i}(x) & =\frac{\psi_{i}(x)}{\sqrt{N_{i}}}, & & \text { normalized eigenfunctions; } \\
N_{i} & =\int_{0}^{L_{x}} w(x) \psi_{i}^{2}(x) d x, & & \text { normalization integrals; } \\
\bar{g}_{i}(t) & =\int_{0}^{L_{x}} P(x, t) \tilde{\psi}_{i}(x) d x, & & \text { transformed source terms. }
\end{aligned}
$$

The generalized integral transform technique (GITT) is employed here in the solution of the Sturm-Liouville problem (Eqs. (4a)-(4c) via the proposition of a simpler auxiliary eigenvalue problem and expanding the unknown eigenfunctions in terms of the chosen basis [19]. Also, the variable equation coefficients are themselves expanded in terms of known eigenfunctions [19], so as to allow for a fully analytical implementation 
of the coefficients matrices in the transformed system. For instance, the coefficients are expanded in terms of eigenfunctions, together with a filtering solution to enhance convergence, in the following form:

$$
\begin{aligned}
w(x) & =w_{f}(x)+\sum_{k=1}^{\infty} \tilde{\Gamma}_{k}(x) \bar{w}_{k}, & & \text { inverse; } \\
\bar{w}_{k} & =\int_{0}^{L_{x}} w^{*}(x)\left[w(x)-w_{f}(x)\right] \tilde{\Gamma}_{k}(x) d x, & & \text { transform; } \\
k(x) & =k_{f}(x)+\sum_{k=1}^{\infty} \tilde{\Gamma}_{k}(x) \bar{k}_{k}, & & \text { inverse; } \\
\bar{k}_{k} & =\int_{0}^{L_{x}} w^{*}(x)\left[k(x)-k_{f}(x)\right] \tilde{\Gamma}_{k}(x) d x, & & \text { transform; } \\
d(x) & =d_{f}(x)+\sum_{k=1}^{\infty} \tilde{\Gamma}_{k}(x) \bar{d}_{k}, & & \\
\bar{d}_{k} & =\int_{0}^{L_{x}} w^{*}(x)\left[d(x)-d_{f}(x)\right] \tilde{\Gamma}_{k}(x) d x, & & \text { transform; }
\end{aligned}
$$

where $w^{*}(x)$ is the weighting function for the chosen normalized eigenfunction $\tilde{\Gamma}_{k}(x)$. The expansion basis may be chosen employing the same auxiliary problem but with firstorder boundary conditions, while the filtering function could be a simple analytic function that satisfies the boundary values for the original coefficients or just an average value of the respective coefficient. The transformed coefficients in Eqs. (6a), (6c), and (6e) will then be the parameters to be estimated, together with the boundary or average values in the proposed filter expression.

\section{INVERSE PROBLEM SOLUTION}

In the Bayesian approach, inference is drawn by constructing the joint probability distribution of all unobserved quantities based on all that is known about them. This knowledge incorporates previous information about the phenomena under study and is also based on values of observed quantities when they are available. This approach is based on Bayes' theorem, which can be written as [10, 12]

$$
p(\mathbf{P} \mid \mathbf{Y})=\frac{p(\mathbf{Y} \mid \mathbf{P}) p(\mathbf{P})}{p(\mathbf{Y})} .
$$

In summary, solving an inverse problem within the Bayesian framework may be broken into three subtasks: (1) based on all information available for the unknown $\mathbf{P}$, find a prior probability density $p(\mathbf{P})$ that reflects judiciously this prior information; (2) find the likelihood function $p(\mathbf{Y} \mid \mathbf{P})$ that describes the interrelation between the observations and the unknowns; and (3) develop methods to explore the posterior probability density $p(\mathbf{P} \mid \mathbf{Y})$. 
When it is not possible to analytically obtain the corresponding posterior distributions, one needs to use a method based on simulation. The inference based on simulation techniques uses samples from the posteriori $p(\mathbf{P} \mid \mathbf{Y})$ to extract information about them. Several sampling strategies are proposed in the literature, including the MCMC adopted in this work.

The most commonly used MCMC sampling algorithms is the Metropolis-Hastings, which is employed here [10,12]. The Metropolis-Hastings algorithm uses the same idea of the rejection methods; i.e., a value is generated from an auxiliary distribution and accepted with a given probability. This correction mechanism ensures the convergence of the chain to the equilibrium distribution.

The unknown quantities in this work, the variable thermal properties, and the effective heat transfer coefficient were expressed as eigenfunction expansions, which significantly reduces the number of parameters. The truncation orders and the choices of filtering functions in the proposed expansions (Eqs. (6a)-(6f)) govern the number of parameters to be estimated. Thus, the total number of parameters $N_{P}$ is given by the sum of parameters in each expansion, including the number of parameters in each filter and the number of parameters in the heat flux expression, also to be estimated eventually, as

$$
N_{P}=N_{P k}+N_{P w}+N_{P d}+N_{q}
$$

or

$$
N_{P}=\left(N_{k F}+N_{k}\right)+\left(N_{w F}+N_{w}\right)+\left(N_{d F}+N_{d}\right)+N_{q}
$$

Another important aspect of the present study is the solution of the inverse problem in the transformed field from the integral transformation of the experimental temperature data, thus compressing the experimental measurements in the space variables into a few transformed temperature modes. Once the experimental temperature spatially distributed readings have been obtained, one proceeds to the integral transformation of the temperature field at each time through the integral transform pair below:

$$
\begin{aligned}
\text { Transform: } & \bar{T}_{\exp , i}(t)=\int_{0}^{L x} w(x) \tilde{\psi}_{i}(x)\left[T_{\exp }(x, t)-T_{\infty}\right] d x, \\
\text { Inverse: } & T_{\exp }(x, t)=T_{\infty}+\sum_{i=0}^{N i} \tilde{\psi}_{i}(x) \bar{T}_{\exp , i}(t) .
\end{aligned}
$$

Both the direct and inverse problems solutions were implemented in the symbolicnumerical computation platform Mathematica [22].

\section{EXPERIMENTAL SET-UP AND PROCEDURE}

The experimental set-up presented in Figure 2 employs temperature measurements obtained from the FLIR SC660 infrared camera, a high-performance infrared system with $640 \times 480$ image resolution and $-40^{\circ} \mathrm{C}$ to $1,500^{\circ} \mathrm{C}$ temperature range. The main components of the set-up are marked on Figure 2a as (a) infrared camera (FLIR SC660), (b) camera stand for vertical experiment configuration, (c) frame with sandwiched heated 


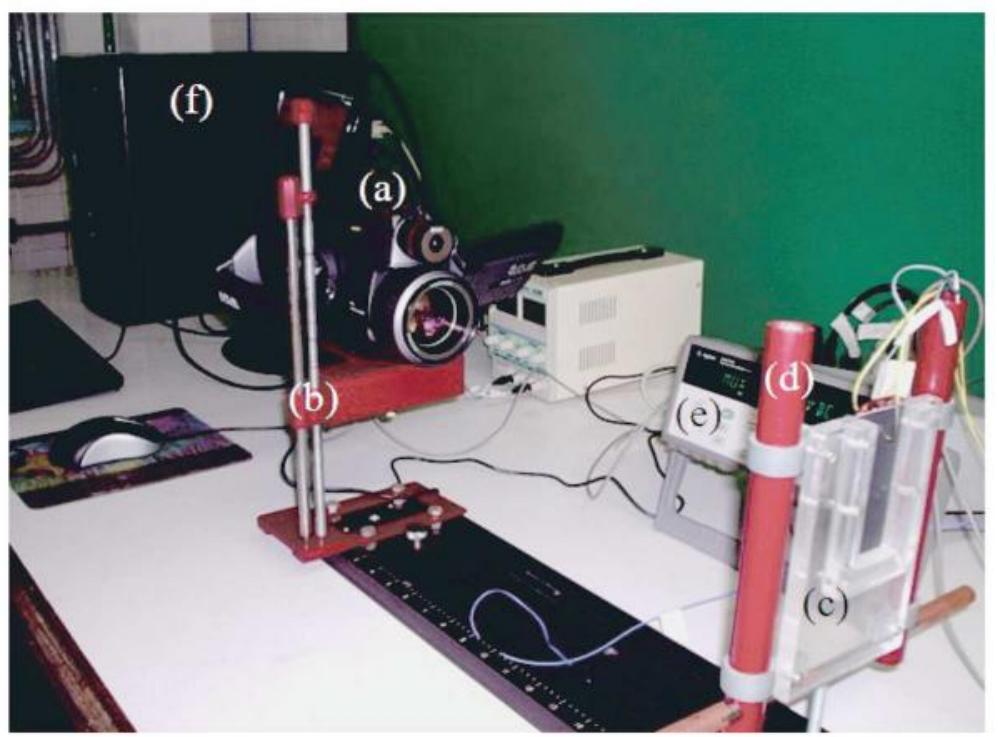

(a)

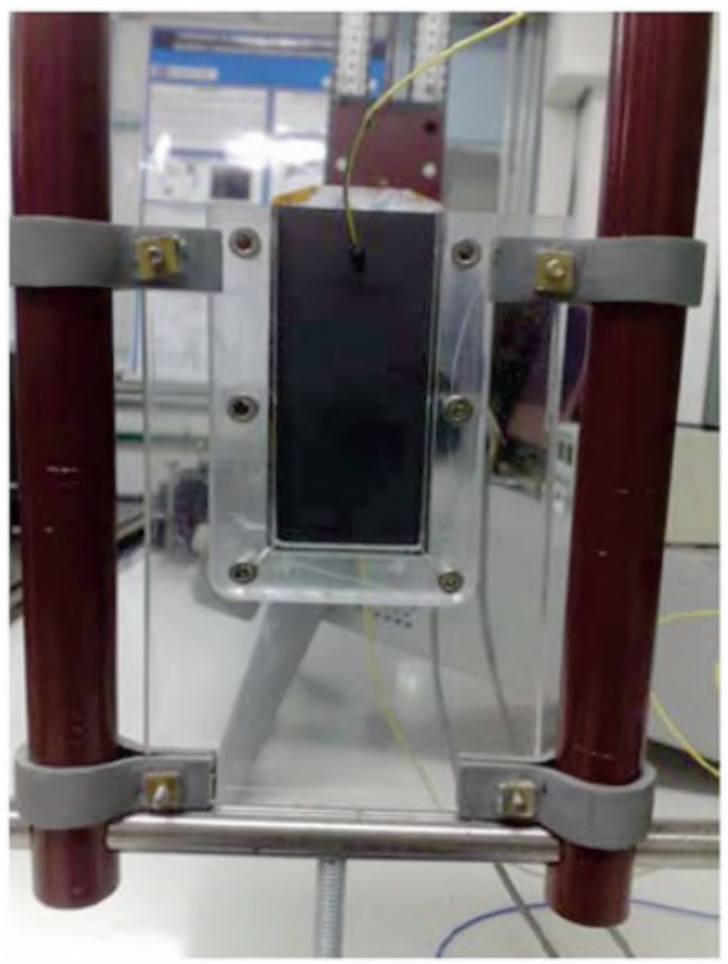

(b)

Figure 2. (a) General view of the experimental set-up for the infrared thermography analysis: (a-infrared camera [FLIR SC660], b-camera stand for vertical experiment configuration, c-frame with sandwiched heated plates, d-sample support, e-data acquisition system [Agilent 34970-A], f-microcomputer for data acquisition). (b) Detailed view of the sandwiched plates frame and support. (color figure available online) 
plates, (d) sample support, (e) data acquisition system (Agilent 34970-A, Agilent Technologies, USA), and (f) microcomputer for data acquisition. The plate set-up, detailed in Figure $2 b$, consists of two identical small plates, with lateral and vertical dimensions of $40 \times 80 \mathrm{~mm}$. An electrical resistance $(38.2 \Omega)$ was employed in the heating of the plates at their contact interface, with the same lateral dimensions as of the plates but half the length $(40 \times 40 \mathrm{~mm})$, joined at the upper half of the plate's height. The resistance is sandwiched between two identical plates, with the aid of a thermal compound paste and kept in place by the frame with insulated fixing corners. In order to reduce uncertainty in the infrared camera readings, the plate surface that faces the infrared camera was painted with a graphite ink, which brought its emissivity to $\varepsilon=0.97$, as stated by the ink manufacturer. The thickness of the bakelite plates used in the first experiment is $1.68 \mathrm{~mm}$, while the thickness of the polystyrene plates used in the second experiment varies from $1.10 \mathrm{~mm}$ to $1.88 \mathrm{~mm}$. This variation has been verified to be practically linear, as shown in Figure 3, where the measured fluctuations are shown with respect to the expected linear variation between the edge values. The plate thicknesses were measured with the aid of a profilemeter Taylor Hobson Form TalySurf PGI 830 (Taylor Hobson [a division of AMETEK, Inc.], USA). The choice of heating the sample plates in the vertical position and at the upper half of its length was a result of the observation of a higher sensitivity in this configuration [21].

The experimental procedure is initiated by prescribing a voltage difference to be imposed on the electrical resistance with a DC voltage regulator. The data acquisition is started, and after a certain number of preliminary measurements to allow for averaging the initial conditions, the DC source switch is turned on to heat the sample plates (a nominal voltage of 8 volts has been applied through the DC source in both experiments). The temperature increase may be followed through the computer monitoring. Figure 4 illustrates the images produced by the FLIR SC660 camera acquisition system, both at the moment the DC source is turned on (Figure 4a) and after some elapsed heating time, when the heated plate image is much brighter (Figure $4 \mathrm{~b}$ ). Once steady state is achieved, the DC source is turned off.

\section{RESULTS AND DISCUSSION}

Before proceeding to the inverse problem analysis based on the obtained experimental results, the findings on the verifications that have been implemented to test the constructed set-up are briefly reported. First, the temperature measurements at both surfaces from three independent experimental runs have demonstrated the repeatability of the experimental procedure, illustrated in Figure 5a. Then, for the bakelite plates experiment, a practically perfect superposition of the temperature measurements was observed by a couple of type-K thermocouples installed at the two sandwiched bakelite plates, on opposite sides, with the infrared camera measurements, which also confirmed the expected symmetry, as shown in Figure 5b. The standard deviation of the three infrared thermography readings, calculated for each acquisition time, was at most $0.11^{\circ} \mathrm{C}$.

The number of pixels in the vertical direction provides an average total number of 328 spatial measurements along the $80-\mathrm{mm}$ plate. Figure 6 illustrates the time evolution of the transformed temperature fields, consecutively numbered up to the tenth transformed potential, as obtained from Eq. (9a). One may clearly observe the more significant role of the first five transformed fields to the temperature expansions. 


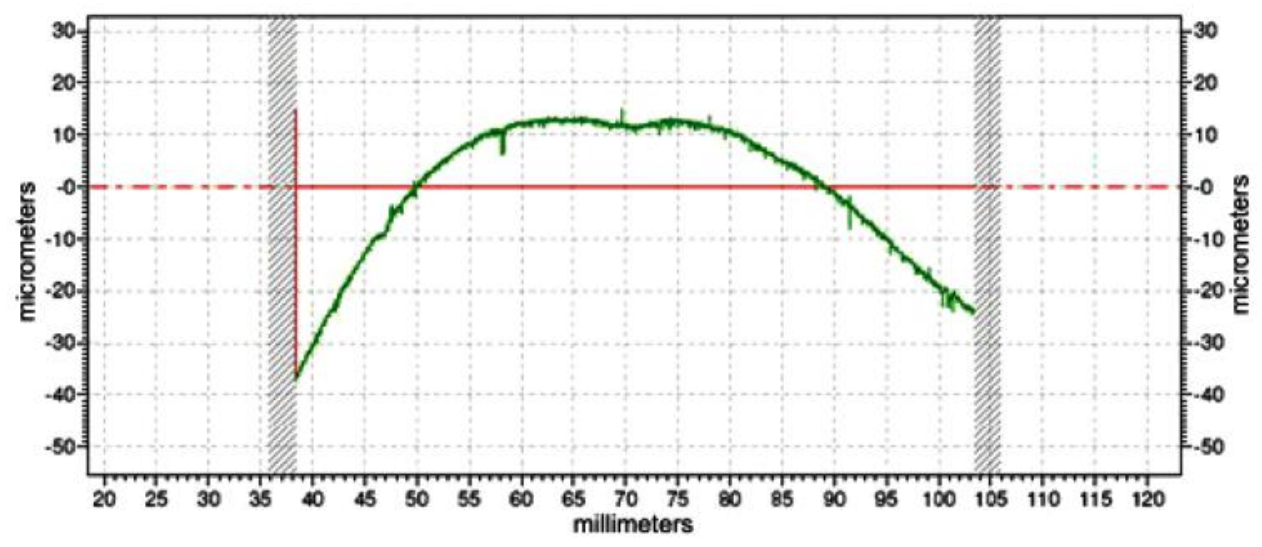

(a)

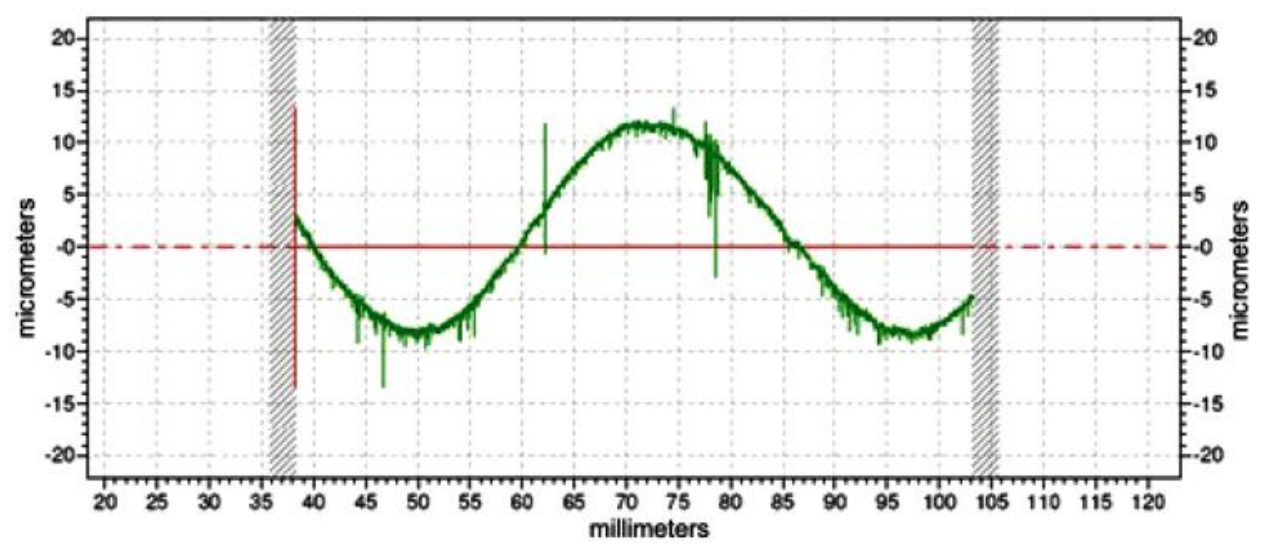

(b)

Figure 3. (a) Fluctuations of the measured thickness with respect to the linear approximation adopted; measurements provided by the profilemeter Taylor Hobson Form TalySurf PGI 830: (a) first polystyrene plate and (b) second polystyrene plate. (color figure available online)

The transformed temperatures are in fact the quantities that are employed in the inverse problem analysis. Therefore, a significant data reduction of more than $95 \%$ is achieved as one chooses to solve the inverse problem in the transformed temperature domain, here employing 226 time measurements. Then the total of 65,600 temperature measurements drops to only 2,260 data points in the transformed domain for a truncation order of $N=10$ temperature modes to be used in the inverse analysis.

The experimental conditions here encountered are expected to fit into the problem formulation described by Eqs. (1a)-(1d), which was adopted in the direct and inverse problem solutions. The time variation of the applied heat flux, which accounts for the thermal capacity of the resistance itself and of the thermal paste, besides the thermal 


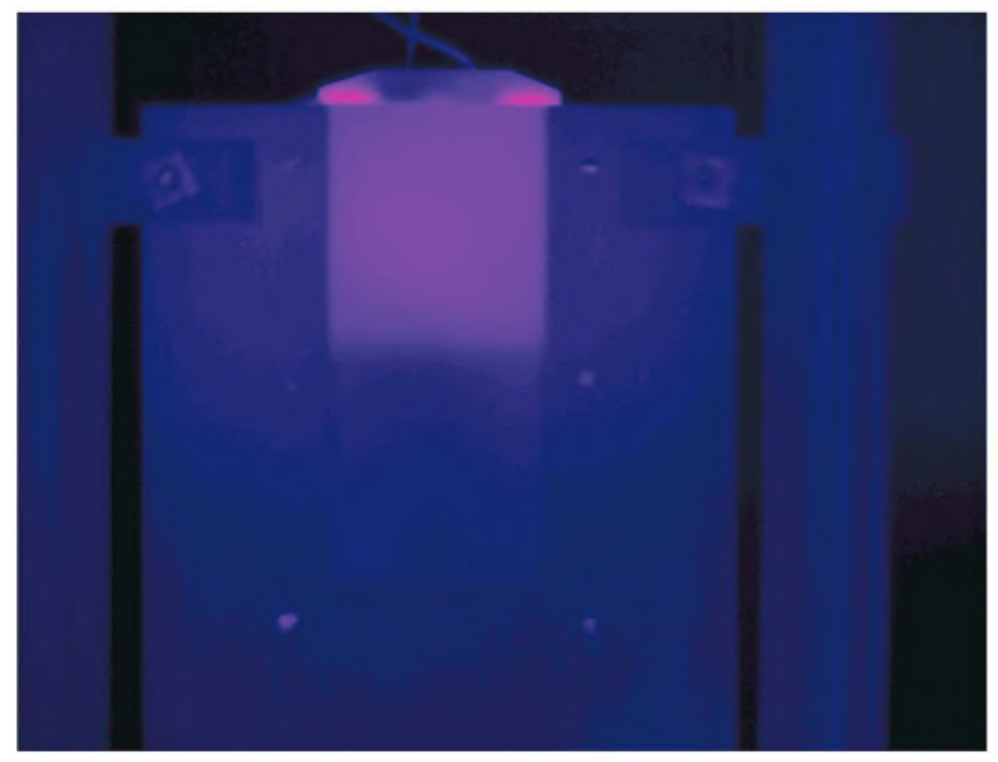

(a)

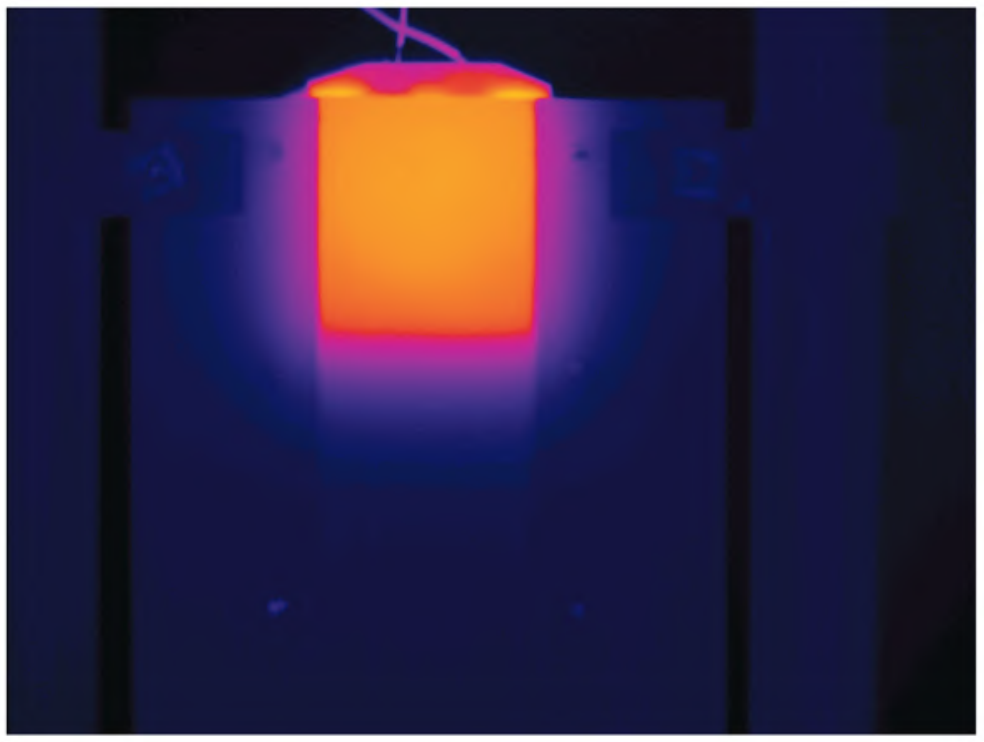

(b)

Figure 4. Infrared camera image: (a) acquired at the moment the DC source is turned on and (b) acquired after some elapsed time during heating period. (color figure available online) 


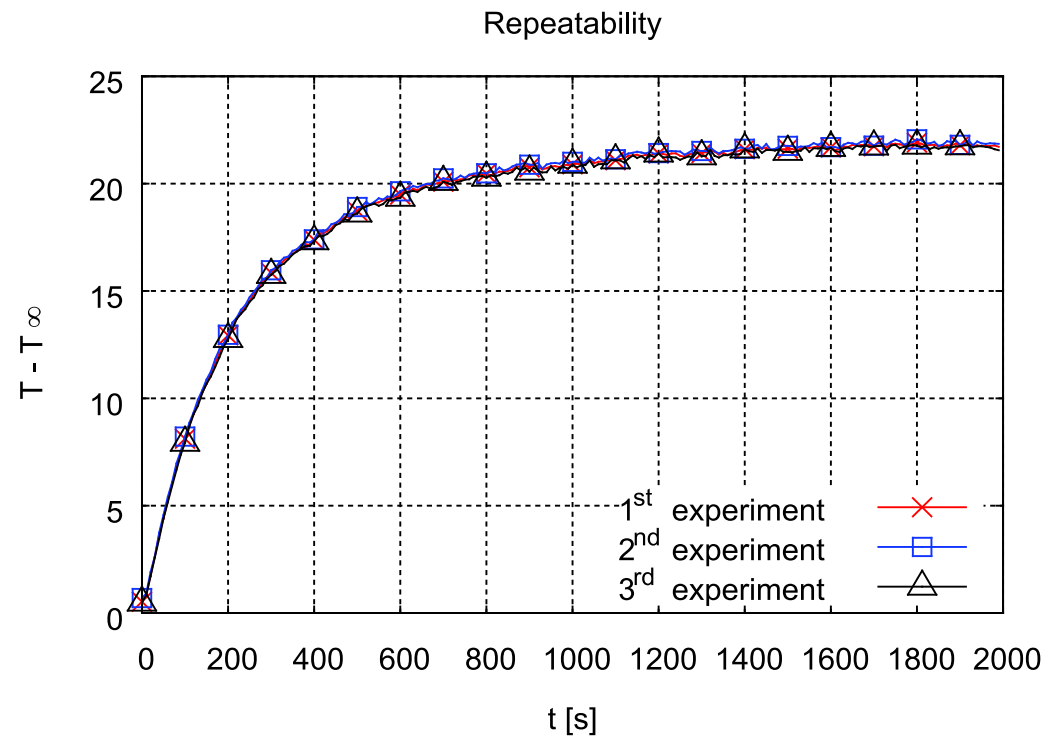

(a)

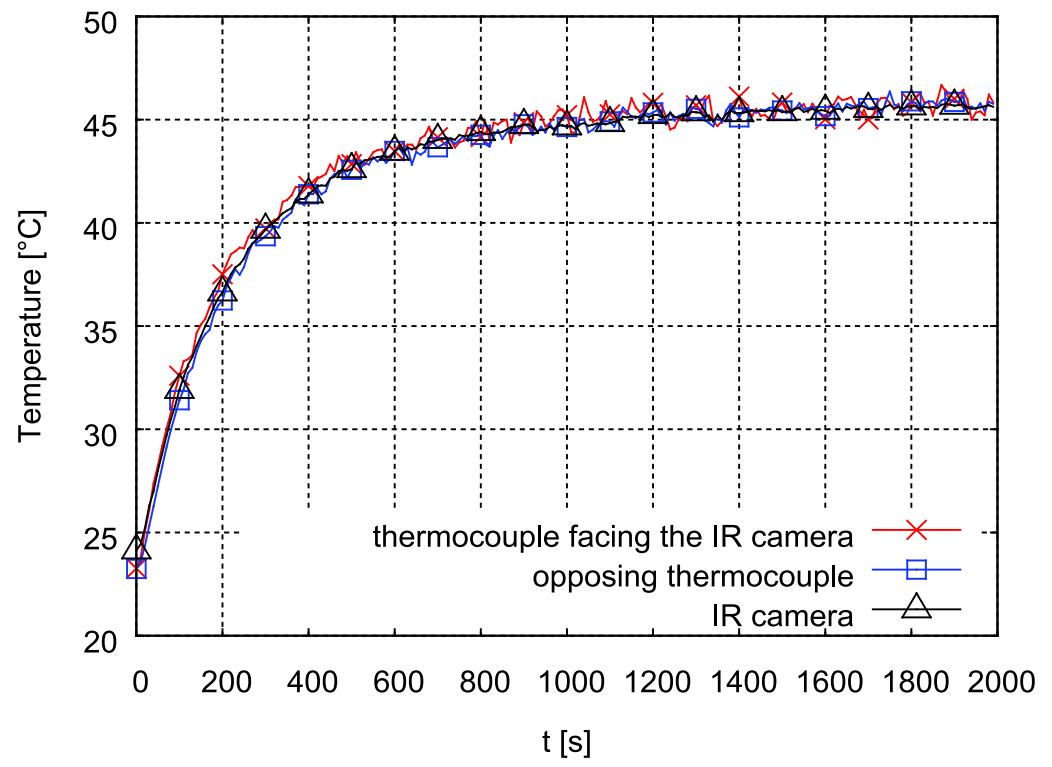

(b)

Figure 5. (a) Repeatability of the experiment and the infrared camera measurements at a fixed position at the heated portion of the bakelite plate for three distinct runs. (b) Comparison of the time evolution of the temperature readings of the two thermocouples at opposing faces of the two bakelite plates and that from the FLIR SC-660 infrared camera. (color figure available online) 


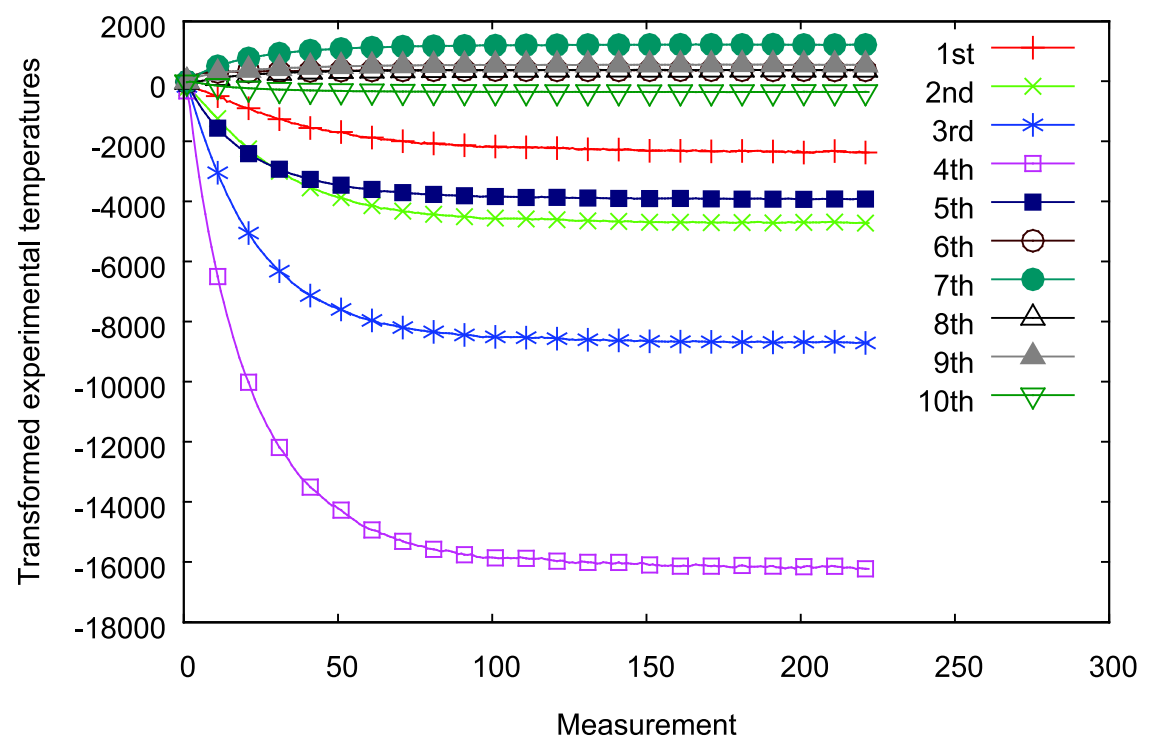

Figure 6. Time evolution of the first ten integral transformed experimental temperatures (bakelite plates). (color figure available online)

contact resistance, has also been parameterized. Therefore, the applied heat flux is here considered to be given by

$$
\begin{aligned}
q(x, t) & =q_{w}(x) f(t), \\
f(t) & =c-a e^{-b t}, \\
q_{w}(x) & =\left\{\begin{array}{ll}
q_{1}, & 0<x<x_{C} \\
q_{2}, & x_{C}<x<L_{x}
\end{array},\right.
\end{aligned}
$$

where the positions $x=0$ and $x=x_{C}=4 \mathrm{~cm}$ correspond to where the electric resistance begins and ends, respectively. Therefore, the unheated portion of the plate corresponds to a heat flux $q_{2}=0$. Since the dissipated power in the resistance is accurately measured, Eq. (1a) is thus divided by $q_{1}$, and then the estimated parameters can be expressed by multiplying each one with the measured heat flux value $q_{1}$ and its associated uncertainty.

The effective heat transfer coefficient has a more involved behavior and has been expanded here in eigenfunctions according to Eqs. (6e) and (6f). In light of the nature of the applied heating, a filter was considered in the form of a step function that assumes two different characteristic values at the heated and unheated plate portions:

$$
h_{e f f}(x)=\left\{\begin{array}{ll}
h_{1} & 0<x<x_{C} \\
h_{2} & x_{C}<x<L_{x}
\end{array} .\right.
$$

The initial estimates were then obtained from correlations for natural convection over vertical plates and linearization of the radiative heat flux. As previously discussed, the 
expansion truncation orders govern the number of parameters involved in the estimation procedure. Here, the total number of parameters refers to the filters and expansions for the thermal conductivity, heat capacity, and effective heat transfer coefficient. Also, parameters $a, b$, and $c$ in Eqs. (10a)-(10c), which control the time variation of the applied heat flux, are included:

$$
\begin{gathered}
\mathbf{P}=\left[\left(k_{x 0}, k_{x L}, \bar{k}_{1}, \bar{k}_{2}, \ldots, \bar{k}_{N_{k}}\right),\left(w_{x 0}, w_{x L}, \bar{w}_{1}, \bar{w}_{2}, \ldots, \bar{w}_{N_{w}}\right),\right. \\
\left.\left(d_{x 0}, d_{x L}, \bar{d}_{1}, \bar{d}_{2}, \ldots, \bar{d}_{N_{d}}\right), a, b, c\right] .
\end{gathered}
$$

Table 1 presents the parameters and type of a priori information that has been adopted in the inverse problem analysis for the cases presented in this work and for each parameter ( $\mathrm{N}=$ Gaussian distribution, $\mathrm{U}=$ non informative uniform distribution). For the thermal conductivity and heat capacity of the bakelite plates, normal priors have been adopted that are centered in measurements of these properties obtained with a flash method set-up (the Netzsch nanoflash LFA 447 [Erich NETZSCH GmbH \& Co. Holding KG, Germany] at the Laboratory of Transmission and Technology of Heat [LTTC], Universidade Federal do Rio de Janeiro [UFRJ]) [20], namely $w=1.768 \times$ $10^{6} \mathrm{~J} / \mathrm{m}^{3 \circ} \mathrm{C}$ and $k=0.279 \mathrm{~W} / \mathrm{m}^{\circ} \mathrm{C}$ with $5 \%$ standard deviation. For the effective thermophysical properties of the polystyrene plates, literature values [23] have been adopted, i.e., $w=1.3 \times 10^{6} \mathrm{~J} / \mathrm{m}^{3 \circ} \mathrm{C}$ and $k=0.116 \mathrm{~W} / \mathrm{m}^{\circ} \mathrm{C}$ with $15 \%$ standard deviation. Also, normal priors were employed for the two values of the parameters in the filter of the effective heat transfer coefficients $h_{x 0}$ and $h_{x L}$, provided by available correlations of natural convection and linearized radiation. For the remaining parameters $\left(\bar{k}_{1}, \bar{w}_{1}, \bar{h}_{1}, \bar{h}_{2}, \bar{h}_{3}, a, b, c\right)$, non informative priors have been adopted. It should be stressed that in the case of a homogeneous material, such as the first experiment investigated in this work, in which identical homogeneous bakelite plates are used, one expects to obtain estimates for $k_{x L}$ and $w_{x L}$ very close to $k_{x 0}$ and $w_{x 0}$, respectively.

In the other experiment investigated in this work, in which polystyrene plates with spatially variable thickness are used, one expects to obtain effective thermophysical properties the spatial variations of which are given by the thickness variation (Eqs. (2a)-(2c)). Three cases were more closely analyzed. Case 1 is the homogeneous material situation with the two identical bakelite plates. Cases 2 and 3 correspond to the polystyrene plates with variable thickness but invert the heated portion of the plate for comparison purposes; namely, case 2 stands for the situation of heating of the thicker portion of the plate (increasing thickness), while case 3 stands for heating of the thinner portion (decreasing thickness).

Table 2 presents the initial values employed for each parameter to be estimated, as well as the minimum and maximum allowable limits in the search algorithm. The

\begin{tabular}{|c|c|}
\hline$P$ & Priori $^{a}$ \\
\hline$k_{x 0}, k_{x L}, \bar{k}_{1}, w_{x 0}, w_{x L}, \bar{w}_{1}, h_{x 0}, h_{x L}, \bar{h}_{1}, \bar{h}_{2}, \bar{h}_{3}, a, b, c$ & $\mathrm{~N}, \mathrm{~N}, \mathrm{U}, \mathrm{N}, \mathrm{N}, \mathrm{U}, \mathrm{N}, \mathrm{N}, \mathrm{U}, \mathrm{U}, \mathrm{U}, \mathrm{U}, \mathrm{U}, \mathrm{U}$ \\
\hline
\end{tabular}

Table 1. Definition of parameters to be estimated and type of priors adopted 
Table 2. Initial values of the parameters to be estimated and allowable minimum and maximum limits in each case

\begin{tabular}{llll}
\hline \multicolumn{1}{c}{$P$} & \multicolumn{1}{c}{ Case $1^{a}$} & \multicolumn{1}{c}{ Case $2^{b}$} & \multicolumn{1}{c}{${\text { Case } 3^{c}}^{c}$} \\
\hline$k_{x 0}\left(\mathrm{~W} / \mathrm{m}^{\circ} \mathrm{C}\right)$ & $0.2789[0.2,0.4]$ & $0.0678[0.04,0.15]$ & $0.116[0.08,0.25]$ \\
$k_{x L}\left(\mathrm{~W} / \mathrm{m}^{\circ} \mathrm{C}\right)$ & $0.2789[0.2,0.4]$ & $0.116[0.08,0.25]$ & $0.0678[0.04,0.15]$ \\
$\bar{k}_{1}$ & $0[-1,1] \times 10^{-7}$ & $0[-1,1] \times 10^{-7}$ & $0[-1,1] \times 10^{-7}$ \\
$w_{x 0}\left(\mathrm{~J} / \mathrm{m}^{3 \circ} \mathrm{C}\right)$ & $1.768[1.44,2.55] \times 10^{6}$ & $8.2[5.7,10.6] \times 10^{5}$ & $1.4[0.98,1.82] \times 10^{6}$ \\
$w_{x L}\left(\mathrm{~J} / \mathrm{m}^{3 \circ} \mathrm{C}\right)$ & $1.768[1.442 .55] \times 10^{6}$ & $1.4[0.98,1.82] \times 10^{6}$ & $8.2[5.7,10.6] \times 10^{5}$ \\
$\bar{w}_{1}$ & $0[-1,1] \times 10^{-7}$ & $0[-1,1] \times 10^{-7}$ & $0[-1,1] \times 10^{-7}$ \\
$h_{x 0}\left(\mathrm{~W} / \mathrm{m}^{2 \circ} \mathrm{C}\right)$ & $16.518[8.259,41.294]$ & $16.518[8.259,41.294]$ & $16.518[8.259,41.294]$ \\
$h_{x L}\left(\mathrm{~W} / \mathrm{m}^{2 \circ} \mathrm{C}\right)$ & $5.902[0,20.345]$ & $5.902[0,20.345]$ & $5.902[0,20.345]$ \\
$\bar{h}_{1}$ & $0[-18.112,18.112]$ & $0[-18.112,18.112]$ & $0[-18.112,18.112]$ \\
$\bar{h}_{2}$ & $0[-4.528,4.528]$ & $0[-4.528,4.528]$ & $0[-4.528,4.528]$ \\
$\bar{h}_{3}$ & $0[-6.038,6.038]$ & $0[-6.038,6.038]$ & $0[-6.038,6.038]$ \\
$a$ & $0.5[0,1]$ & $0.5[0,1]$ & $0.5[0,1]$ \\
$b$ & $0.01[0,0.1]$ & $0.01[0,0.1]$ & $0.01[0,0.1]$ \\
$c$ & $1[0,1]$ & $1[0,1]$ & $1[0,1]$ \\
\hline
\end{tabular}

\footnotetext{
${ }^{a}$ Bakelite plates experiment.

${ }^{b}$ Polystyrene plates with increasing thickness experiment.

${ }^{c}$ Polystyrene plates with decreasing thickness experiment.
}

initial values were proposed from the available a priori information and from natural convection correlations available in the literature. Markov chains of up to 120,000 states were achieved, neglecting the first 40,000 states needed for the warm up of the chains.

Table 3 presents the values of the thermophysical properties estimated in each of the three cases, together with their respective $99 \%$ confidence intervals. It is observed that the uniform distributions of both the thermal conductivity and heat capacity were practically recovered for the bakelite plates experiment, with very close values encountered at the two edges of the plate, as shown in the first case in Table 3. This observation is also confirmed in Figures $7 \mathrm{a}$ and $7 \mathrm{~b}$ by the essentially uniform behaviors of both the thermal conductivity and heat capacity, respectively, with the corresponding $99 \%$ confidence intervals and the expected reference values obtained by the flash method. Figure $7 \mathrm{c}$ depicts the residuals between calculated and experimental quantities for the first five transformed temperature modes in case 1. Although presenting some correlation, which results from the integral transformation procedure that is truncated at a low order of ten modes, the residuals are small. Similar behavior can be observed with the residuals in the temperature field, presented in Figure $7 d$ at three different positions. Similar behavior was observed for the residuals of cases 2 and 3, which are omitted here for the sake of brevity.

With respect to case 2, the results from Table 3 lead to a ratio of thermophysical properties at the two edges of $k\left(L_{x}\right) / k(0)=1.698$ and $w\left(L_{x}\right) / w(0)=1.6912$, while a ratio of $k\left(L_{x}\right) / k(0)=w\left(L_{x}\right) / w(0)=1.707$ is achieved just by taking the thicknesses ratio at the two extremes. Similarly, for case 3 , the estimated ratios are given by $k(0) / k\left(L_{x}\right)=1.685$ and $w(0) / w\left(L_{x}\right)=1.683$, again very close to the reference value of 1.707 . Figures $8 \mathrm{a}$ and $8 \mathrm{~b}$ depict the estimated effective thermophysical properties, thermal conductivity, and heat capacity, respectively, for the polystyrene plates experiment for case 2 of increasing thickness (the thicker portion of the plates are placed in the upper 
Table 3. Estimated values and $99 \%$ confidence intervals for the thermal properties, filters, and other parameters in each case

\begin{tabular}{|c|c|c|c|}
\hline$P$ & Case $1^{a}$ & Case $2^{b}$ & Case $3^{c}$ \\
\hline$k_{x 0}\left(\mathrm{~W} / \mathrm{m}^{\circ} \mathrm{C}\right)$ & $\begin{array}{l}0.2809 \\
{[0.2807,0.2810]}\end{array}$ & $\begin{array}{l}0.06484 \\
{[0.0619,0.0678]}\end{array}$ & $\begin{array}{l}0.1122 \\
{[0.1092,0.1152]}\end{array}$ \\
\hline$k_{x L}\left(\mathrm{~W} / \mathrm{m}^{\circ} \mathrm{C}\right)$ & $\begin{array}{l}0.2800 \\
{[0.2798,0.2802]}\end{array}$ & $\begin{array}{l}0.1101 \\
{[0.1071,0.1113]}\end{array}$ & $\begin{array}{l}0.0655 \\
{[0.0636,0.06951]}\end{array}$ \\
\hline $\bar{k}_{1}$ & $\begin{array}{l}-1.2 \times 10^{-10} \\
{[-5.2,2.1] \times 10^{-10}}\end{array}$ & $\begin{array}{l}-1.1 \times 10^{-13} \\
{[-2.1,-0.78] \times 10^{-13}}\end{array}$ & $\begin{array}{l}-2.0 \times 10^{-12} \\
{[-8.7,4.6] \times 10^{-12}}\end{array}$ \\
\hline$w_{x 0}\left(\mathrm{~J} / \mathrm{m}^{3 \circ} \mathrm{C}\right)$ & $\begin{array}{l}1.7597 \times 10^{6} \\
{[1.7582,1.7617] \times 10^{6}}\end{array}$ & $\begin{array}{l}8.142 \times 10^{5} \\
{[8.140,8.145] \times 10^{5}}\end{array}$ & $\begin{array}{l}1.277 \times 10^{6} \\
{[1.272,1.281] \times 10^{6}}\end{array}$ \\
\hline$w_{x L}\left(\mathrm{~J} / \mathrm{m}^{3 \circ} \mathrm{C}\right)$ & $\begin{array}{l}1.7664 \times 10^{6} \\
{[1.7645,1.7683] \times 10^{6}}\end{array}$ & $\begin{array}{l}1.377 \times 10^{6} \\
{[1.373,1.380] \times 10^{6}}\end{array}$ & $\begin{array}{l}7.588 \times 10^{5} \\
{[7.584,7.592] \times 10^{5}}\end{array}$ \\
\hline $\bar{w}_{1}$ & $\begin{array}{l}-6.2 \times 10^{-12} \\
{[-9.3,4.1] \times 10^{-12}}\end{array}$ & $\begin{array}{l}-1.5 \times 10^{-13} \\
{[-3.2,-0.69] \times 10^{-13}}\end{array}$ & $\begin{array}{l}-3.2 \times 10^{-13} \\
{[-4.9,-0.1] \times 10^{-13}}\end{array}$ \\
\hline$h_{x 0}\left(\mathrm{~W} / \mathrm{m}^{2 \circ} \mathrm{C}\right)$ & $\begin{array}{l}18.75 \\
{[18.72,18.79]}\end{array}$ & $\begin{array}{l}19.103 \\
{[19.063,19.143]}\end{array}$ & $\begin{array}{l}19.487 \\
{[19.451,19.523]}\end{array}$ \\
\hline$h_{x L}\left(\mathrm{~W} / \mathrm{m}^{2 \circ} \mathrm{C}\right)$ & $\begin{array}{l}5.86 \\
{[5.83,5.89]}\end{array}$ & $\begin{array}{l}8.291 \\
{[8.261,8.321]}\end{array}$ & $\begin{array}{l}7.103 \\
{[7.065,7.139]}\end{array}$ \\
\hline $\bar{h}_{1}$ & $\begin{array}{l}-0.29 \\
{[-0.3,-0.278]}\end{array}$ & $\begin{array}{l}-0.7371 \\
{[-0.7382,-0.7361]}\end{array}$ & $\begin{array}{l}-0.4071 \\
{[-0.4087,-0.4055]}\end{array}$ \\
\hline $\bar{h}_{2}$ & $\begin{array}{l}0.16 \\
{[0.15,0.17]}\end{array}$ & $\begin{array}{l}0.6756 \\
{[0.6746,0.6766]}\end{array}$ & $\begin{array}{l}0.1982 \\
{[0.1965,0.1999]}\end{array}$ \\
\hline $\bar{h}_{3}$ & $\begin{array}{l}-0.28 \\
{[-0.294,-0.27]}\end{array}$ & $\begin{array}{l}-0.3965 \\
{[-0.3974,0.3955]}\end{array}$ & $\begin{array}{l}-0.1013 \\
{[-0.1026,-0.0999]}\end{array}$ \\
\hline$a$ & $\begin{array}{l}0.3502 \\
{[0.347,0.353]}\end{array}$ & $\begin{array}{l}0.2617 \\
{[0.2615,0.2620]}\end{array}$ & $\begin{array}{l}0.2823 \\
{[0.2773,0.2873]}\end{array}$ \\
\hline$b$ & $\begin{array}{l}0.004439 \\
{[0.00439,0.00447]}\end{array}$ & $\begin{array}{l}0.003807 \\
{[0.003806,0.003808]}\end{array}$ & $\begin{array}{l}0.003847 \\
{[0.003845,0.003849]}\end{array}$ \\
\hline$c$ & $\begin{array}{l}0.9998 \\
{[0.9994,1]}\end{array}$ & $\begin{array}{l}0.9997 \\
{[0.9996,0.9998]}\end{array}$ & $\begin{array}{l}0.9810 \\
{[0.9809,0.9811]}\end{array}$ \\
\hline
\end{tabular}

\footnotetext{
${ }^{a}$ Bakelite plates experiment.

${ }^{b}$ Polystyrene plates with increasing thickness experiment.

${ }^{c}$ Polystyrene plates with decreasing thickness experiment.
}

heated position). Similarly, Figures $9 \mathrm{a}$ and $9 \mathrm{~b}$ illustrate the same estimated properties for the experiment with decreasing thickness (the thicker edges of the plates are placed in the lower unheated position), case 3 . In both cases, it is observed that the estimated space variations of the thermophysical properties are very close to the expected ones, as illustrated by the reference values obtained from the literature [23] in combination with the thickness variation and the respective $99 \%$ confidence intervals also presented in Figures 8 and 9. It should be stressed that in the cases concerning the polystyrene sample, the reference values considered are mean values obtained from the literature, which are not necessarily the same of the present sample, explaining the fact that, in some cases, the reference values lie outside the estimated confidence intervals at some positions. 


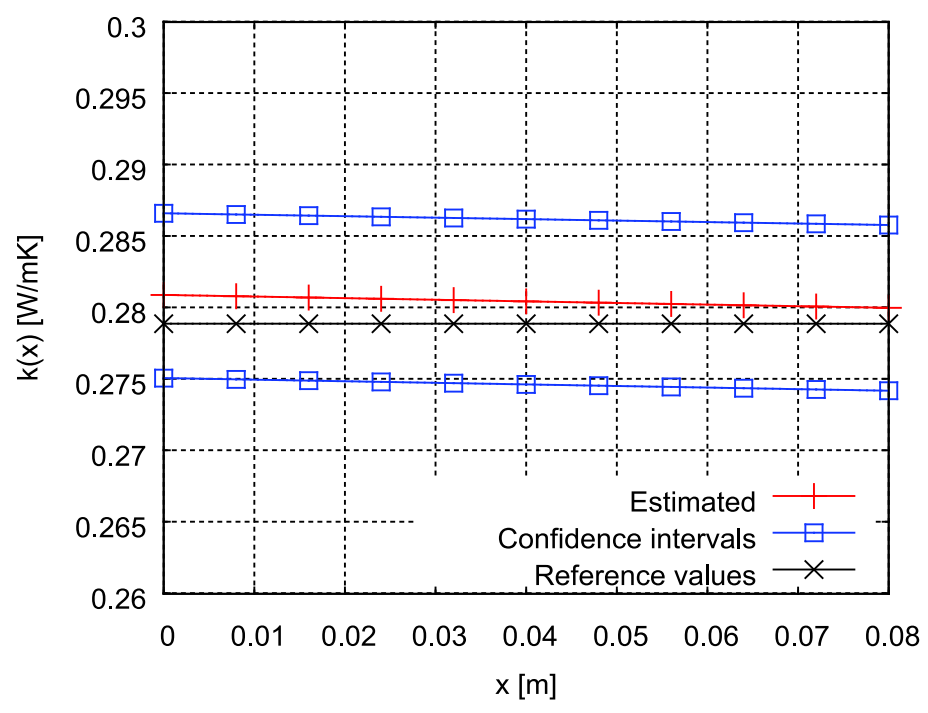

(a)

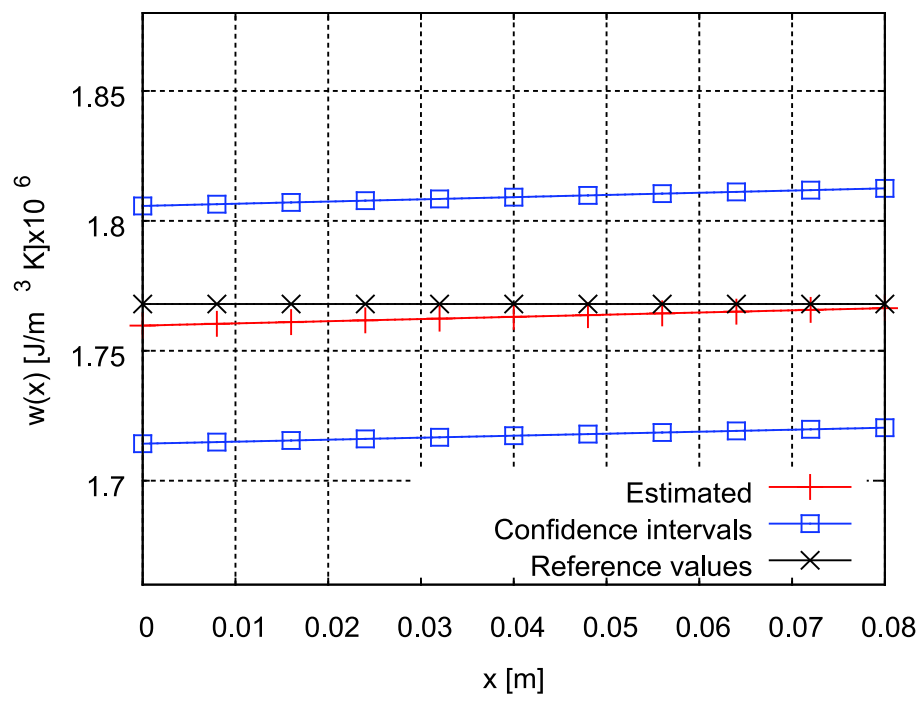

(b)

Figure 7. (a) Estimated thermal conductivity for the bakelite plates in case 1. (b) Estimated heat capacity for the bakelite plates in case 1. (c) Residuals between calculated and experimental quantities for the first five transformed temperature modes for the bakelite plates experiment in case 1. (d) Residuals $\left({ }^{\circ} \mathrm{C}\right)$ between calculated and experimental temperatures at three different positions for the bakelite plates experiment in case 1. (color figure available online) (continued) 


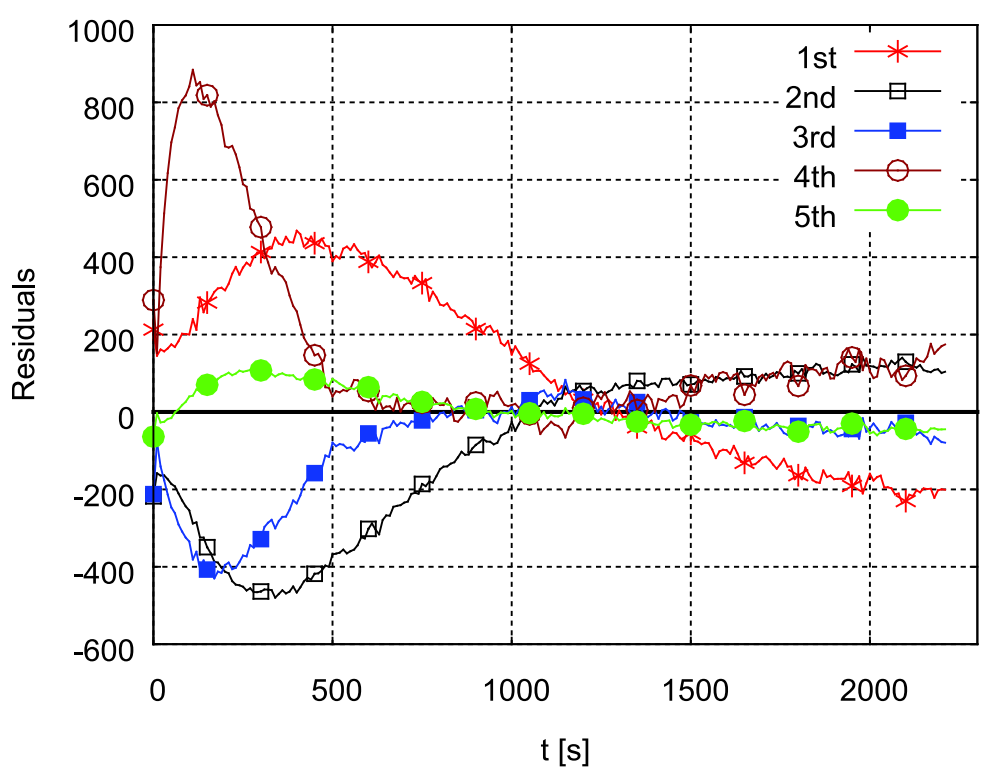

(c)

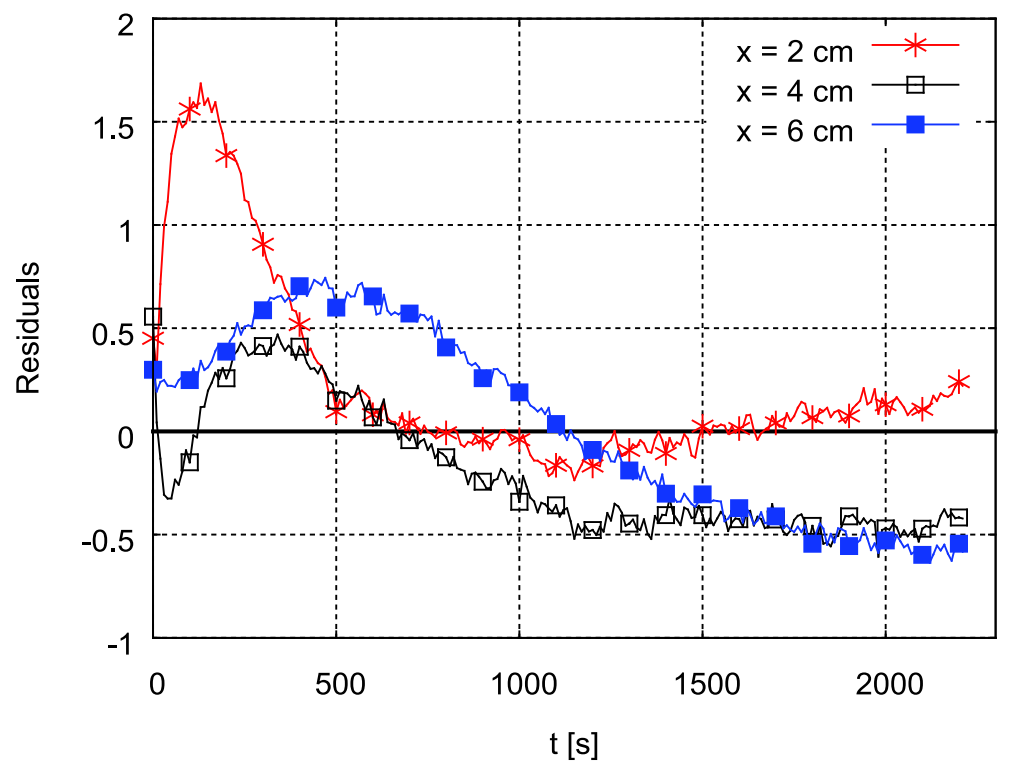

(d)

Figure 7. (Continued) 


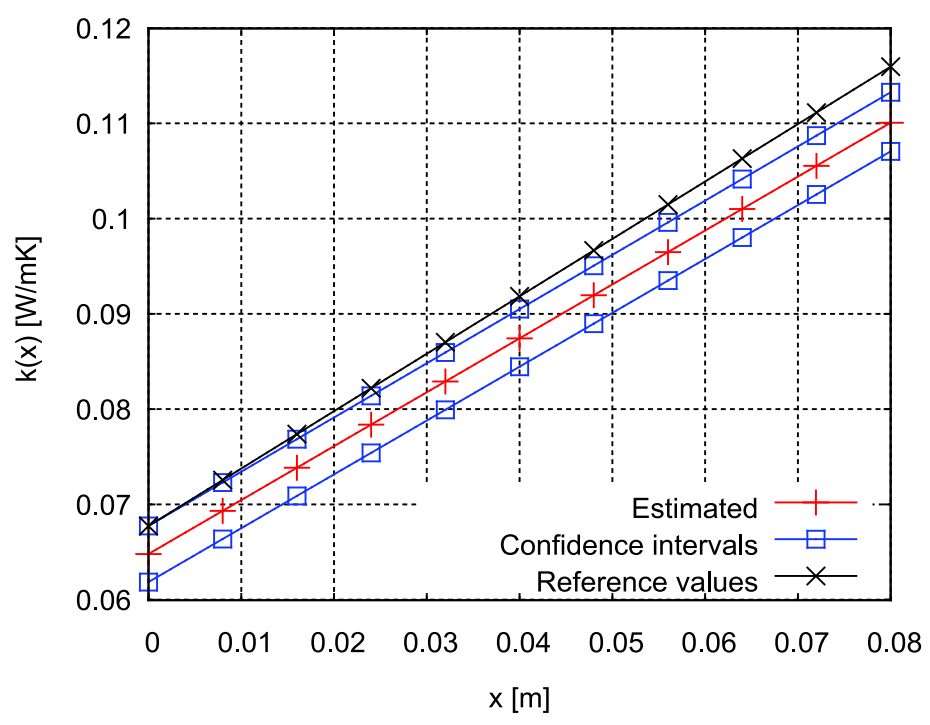

(a)

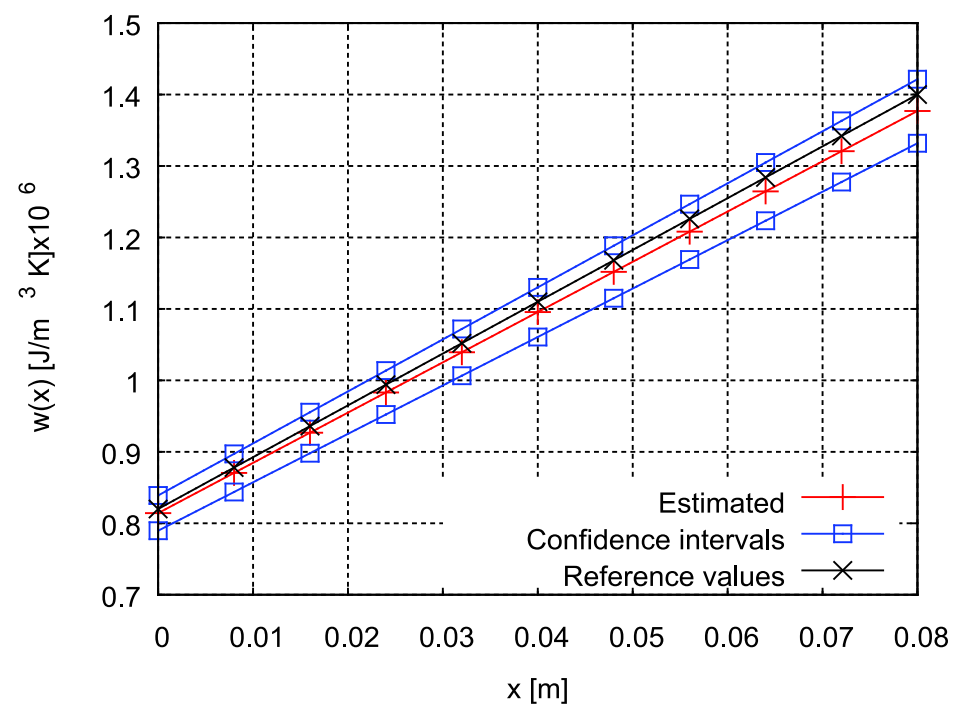

(b)

Figure 8. Polystyrene plates experiment in case 2 with increasing thickness: (a) estimated thermal conductivity and (b) estimated heat capacity. (color figure available online) 


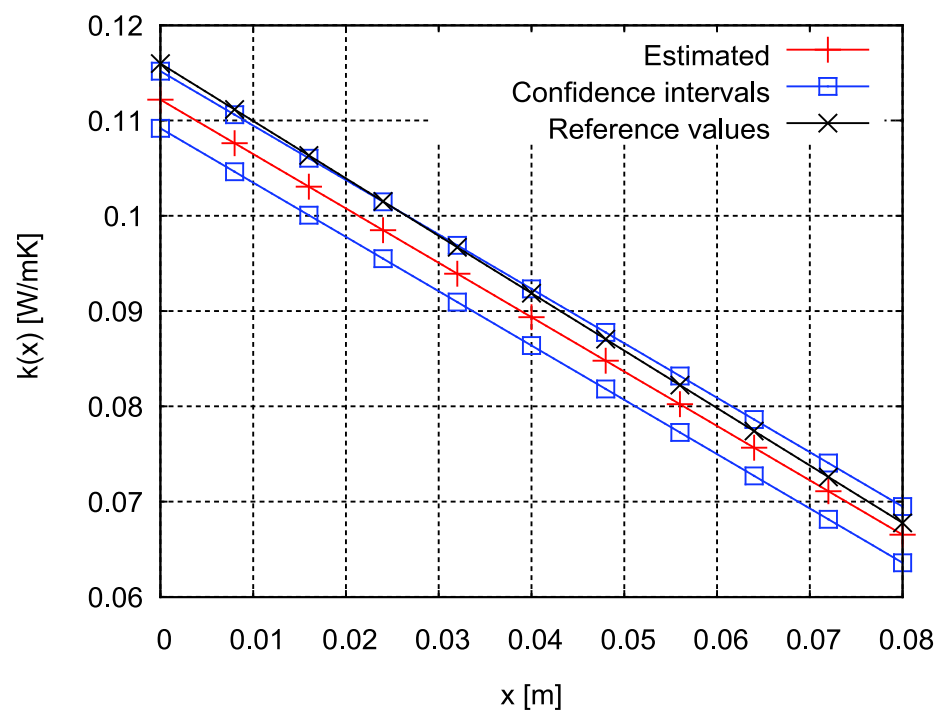

(a)

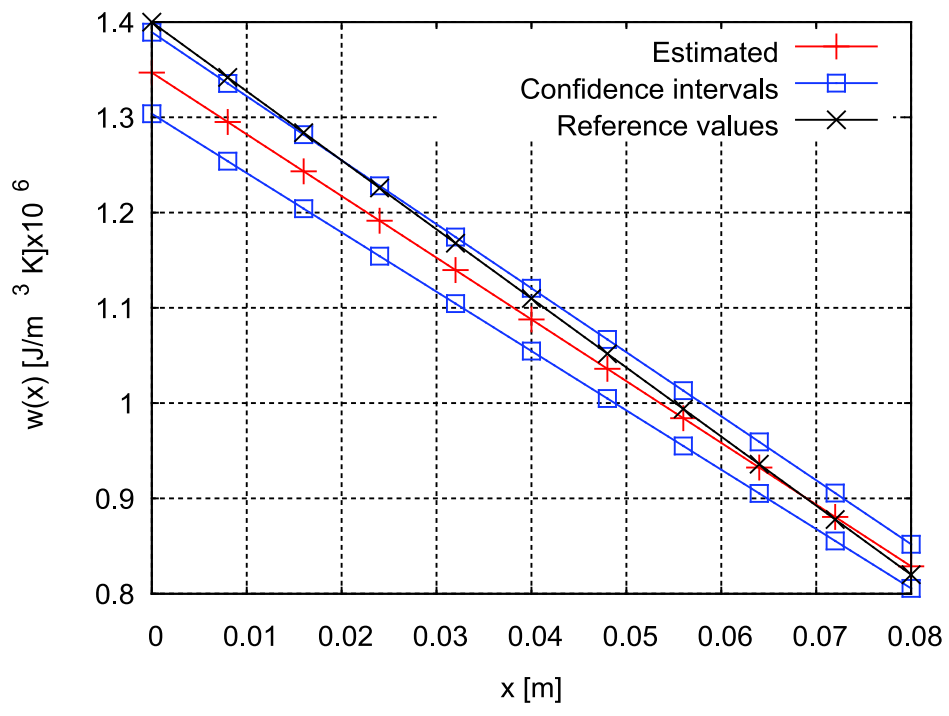

(b)

Figure 9. Polystyrene plates experiment in case 3 with decreasing thickness: (a) estimated thermal conductivity and (b) estimated heat capacity. (color figure available online) 


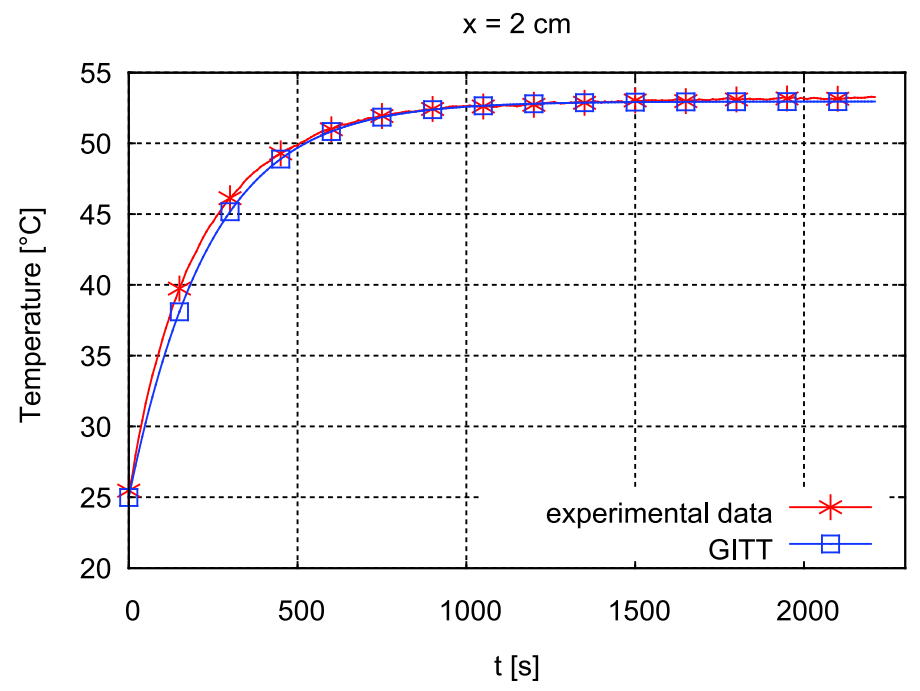

(a)

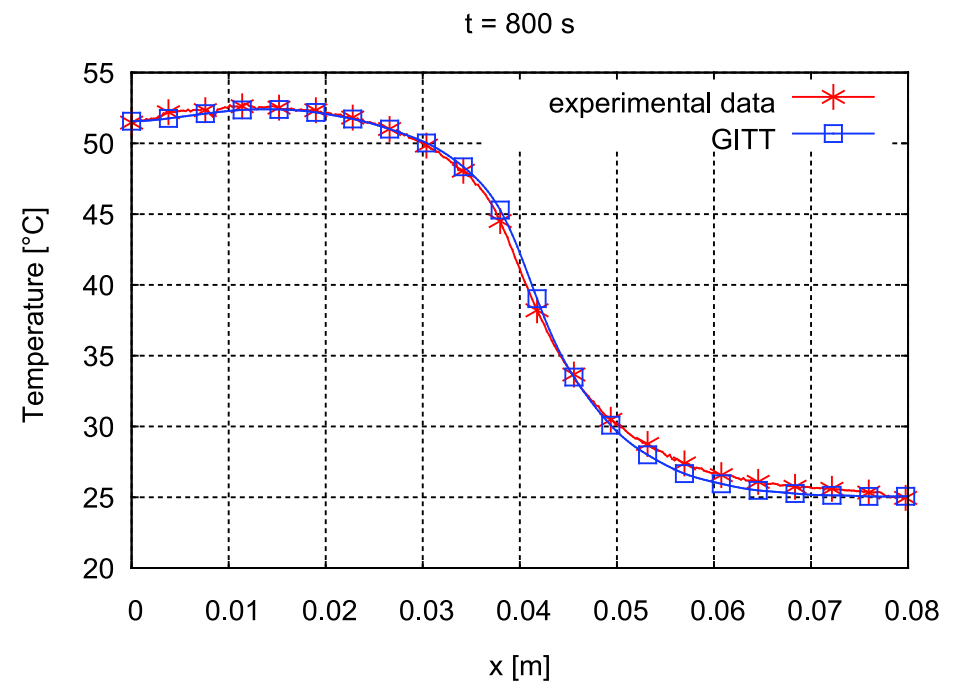

(b)

Figure 10. Bakelite plates experiment, case 1: (a) time evolution of temperature at $x=2 \mathrm{~cm}$ and (b) vertical spatial distribution of temperatures at $t=800 \mathrm{sec}$. (color figure available online)

In order to confirm the estimates obtained, some comparisons are also shown between the experimental temperature field and the theoretical temperatures obtained with another computational code that implements the same class of method in a more general framework [24], using the above estimated parameters as input data. Figures 10a and 10b show a comparison of experimental and theoretical behaviors for, respectively, the time 


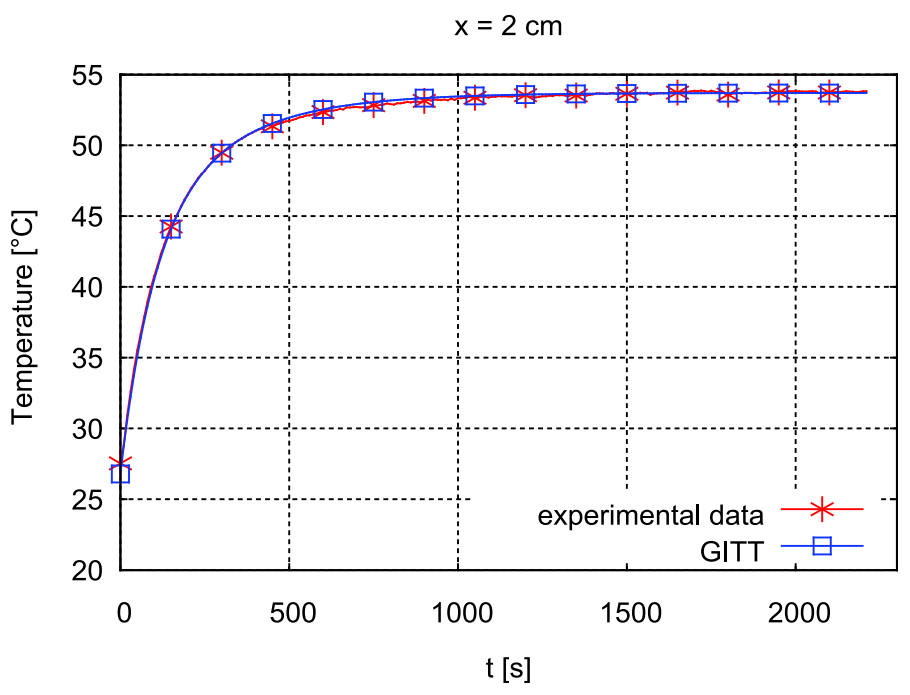

(a)

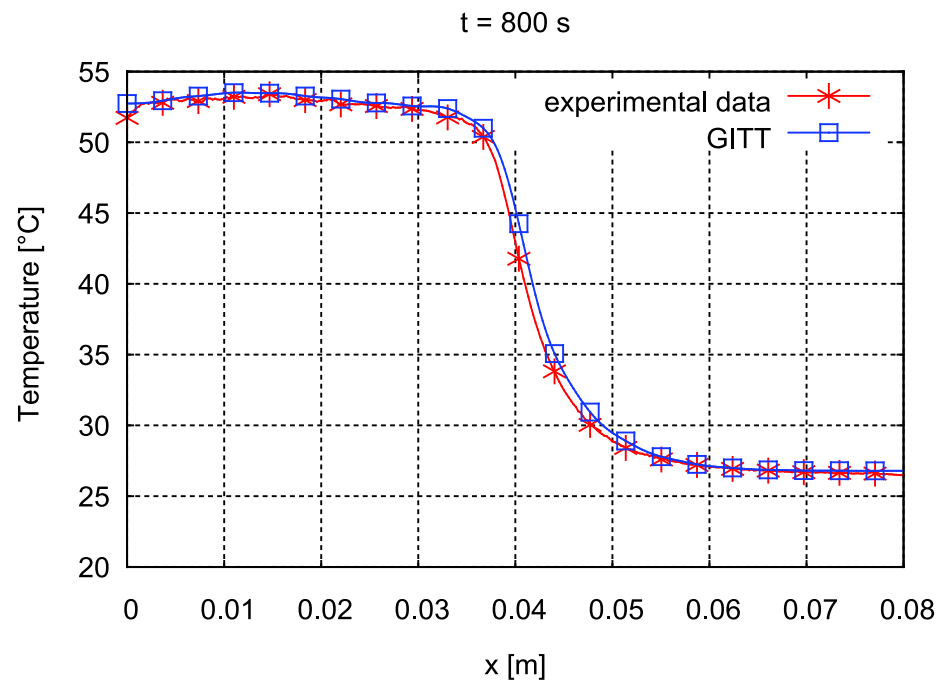

(b)

Figure 11. Polystyrene plates experiment with increasing thickness, case 2: (a) time evolution of temperature at $x=2 \mathrm{~cm}$ and (b) vertical spatial distribution of temperatures at $t=800 \mathrm{sec}$. (color figure available online)

evolution of the temperature at $x=2 \mathrm{~cm}$ up to steady state and for the vertical spatial distribution of the temperature at $t=800 \mathrm{sec}$ for case 1. Similar results are shown in Figures $11 \mathrm{a}$ and $11 \mathrm{~b}$ for case 2, involving the polystyrene plates with increasing thickness, and in Figures 12a and $12 \mathrm{~b}$ for case 3, involving the polystyrene plates with decreasing thickness. In all the three cases, excellent agreement can be observed between 


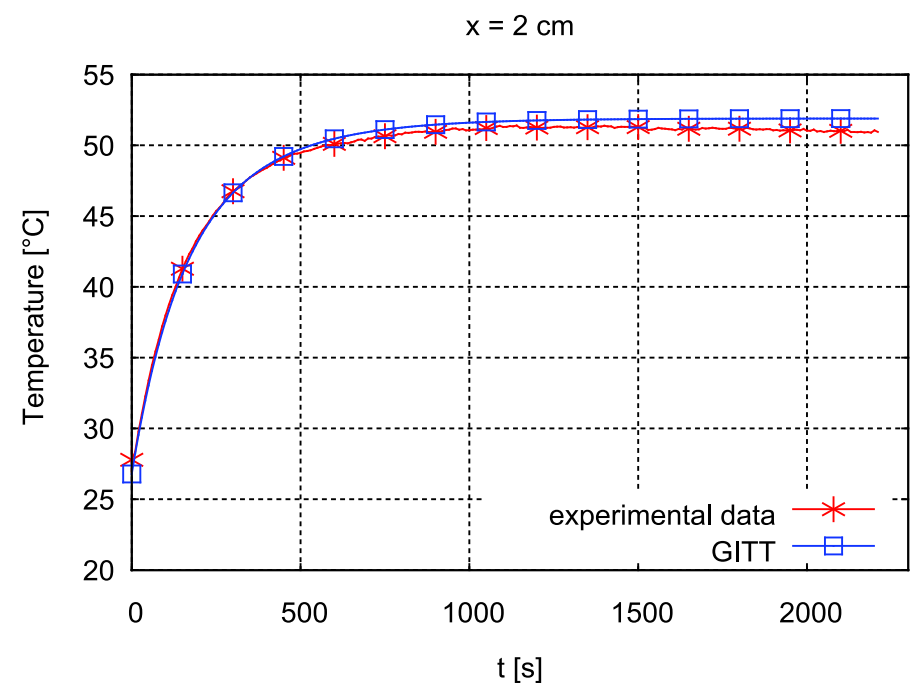

(a)

$t=800 s$

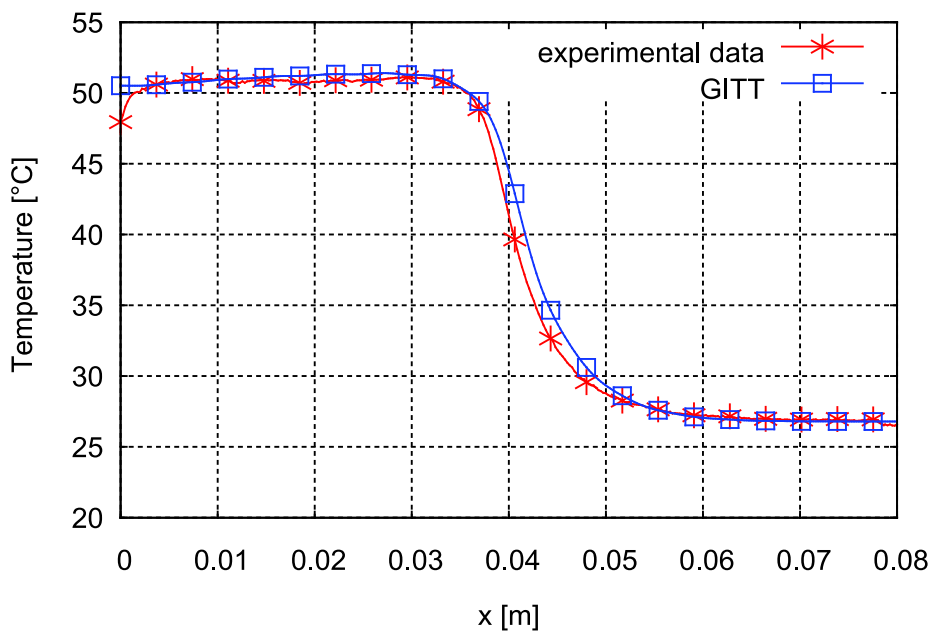

(b)

Figure 12. Polystyrene plates experiment with decreasing thickness case 3: (a) time evolution of temperature at $x=2 \mathrm{~cm}$ and (b) vertical spatial distribution of temperatures at $t=800 \mathrm{sec}$. (color figure available online)

the experimental data and the simulated temperatures calculated using the parameters estimated with the present inverse analysis.

\section{CONCLUSIONS}

The combination of integral transforms for the direct problem solution, Bayesian inference for the inverse problem analysis, and infrared thermography as the temperature 
measurement technique has been demonstrated as a robust and accurate approach toward the simultaneous estimation of variable thermal conductivity, heat capacity, and effective heat transfer coefficient in a transient heat conduction experiment for thermophysical properties identification. A first verification experiment was undertaken employing homogeneous bakelite plates of known thermal conductivity and allowing the inverse problem analysis to automatically identify the thermal properties spatially uniform behavior. A second experiment of polystyrene plates with spatially variable thickness has also been used for verification purposes. The problem has been formulated in such a way that the thickness variation is expressed as a space variation in the thermophysical properties. Again, in this second experiment, the inverse analysis presented here was able to recover the spatial profile of the effective thermophysical properties.

The implemented inverse analysis has two innovative features, which are the representation of the unknown properties as eigenfunction expansions, with the subsequent estimation of the expansions coefficients instead of a swarm of local values, and the integral transformation along the space variable of the temperature measurements, thus compressing the experimental data into a few modes of the transformed temperatures while offering a substantial data reduction that remarkably accelerates the inverse problem algorithm, being particularly interesting in the combined use with the infrared thermography non intrusive technique.

\section{ACKNOWLEDGMENTS}

The authors would like to acknowledge the partial financial support provided by the Brazilian agencies Conselho Nacional de Desenvolvimento Científico e Tecnológico $(\mathrm{CNPq})$ and Coordenação de Aperfeiçoamento de Pessoal de Nível Superior (CAPES). The measurement of the plate thickness variation was performed by the Brazilian National Institute of Metrology (INMETRO).

\section{REFERENCES}

1. S. H. Lin, Transient Conduction in Heterogeneous Media, Int. Comm. Heat Mass Transf., vol. 10, pp. 165-174, 1992.

2. F. Qiulin, X. Xingcheng, H. Xingfang, and G. Jingkun, Calculating Method of the Equivalent Thermal Conductivity of Functionally Gradient Materials, Materials Sci. Eng., vol. A261, pp. 84-88, 1999.

3. O. Fudym, B. Ladevie, and J. C. Batsale, A Seminumerical Approach for Heat Diffusion in Heterogeneous Media: One Extension of the Analytical Quadrupole Method, Num. Heat Transf. Part B Fundamentals, vol. 42, pp. 325-348, 2002.

4. F. Danes, B. Garnier, and T. Dupuis, Predicting, Measuring and Tailoring the Transverse Thermal Conductivity of Composites from Polymer Matrix and Metal Filler, Int. J. Thermophys., vol. 24, pp. 771-784, 2003.

5. D. Kumlutas and I. H. Tavman, A Numerical and Experimental Study on Thermal Conductivity of Particle Filled Polymer Composites, J. Thermoplastic Composite Mater., vol. 19, pp. 441455, 2006.

6. O. Fudym, J. C. Batsale, and J. L. Battaglia, Thermophysical Properties Mapping in SemiInfinite Longitudinally Cracked Plates by Temperature Image Processing, Inverse Prob. Sci. Eng., vol. 15, pp. 163-176, 2007. 
7. O. Fudym, H. R. B. Orlande, M. Bamford, and J. C. Batsale, Bayesian Approach for Thermal Diffusivity Mapping from Infrared Images Processing with Spatially Random Heat Pulse Heating, J. Phys. Conf. Ser. (Online), vol. 135, pp. 12-42, 2008.

8. C. P. Naveira-Cotta, H. R. B. Orlande, and R. M. Cotta, Integral Transforms and Bayesian Inference in the Identification of Variable Thermal Conductivity in Two-Phase Dispersed Systems, Num. Heat Transf. Part B Fundamentals, vol. 57, pp. 173-203, 2010.

9. C. P. Naveira-Cotta, R. M. Cotta, and H. R. B. Orlande, Inverse Analysis with Integral Transformed Temperature Fields for Identification of Thermophysical Properties Functions in Heterogeneous Media, Int. J. Heat Mass Transf., vol. 54, pp. 1506-1519, 2011.

10. J. Kaipio and E. Somersalo, Statistical and Computational Inverse Problems, Springer-Verlag, 2004.

11. N. Zabaras, Inverse Problems in Heat Transfer, in W. J. Minkowycz, E. M. Sparrow, and J. Y. Murthy (Eds.), Handbook of Numerical Heat Transfer, 2nd ed., Wiley, New York, pp. 525-557, 2006.

12. D. Gamerman and H. F. Lopes, Markov Chain Monte Carlo: Stochastic Simulation for Bayesian Inference, 2nd ed., Chapman \& Hall/CRC, Boca Raton, FL, 2006.

13. H. R. B. Orlande, M. J. Colaço, and G. S. Dulikravich, Approximation of the Likelihood Function in the Bayesian Technique for the Solution of Inverse Problems, Inverse Prob. Sci. Eng., vol. 16, pp. 677-692, 2008.

14. R. M. Cotta, Hybrid Numerical-Analytical Approach to Nonlinear Diffusion Problems, Num. Heat Transf. Part B, vol. 127, pp. 217-226, 1990.

15. R. M. Cotta, Integral Transforms in Computational Heat and Fluid Flow, CRC Press, Boca Raton, FL, 1993.

16. R. M. Cotta and M. D. Mikhailov, Heat Conduction: Lumped Analysis, Integral Transforms, Symbolic Computation, Wiley-Interscience, New York, 1997.

17. R. M. Cotta, The Integral Transform Method in Thermal and Fluids Sciences and Engineering, Begell House, New York, 1998.

18. R. M. Cotta and M. D. Mikhailov, Hybrid Methods and Symbolic Computations, in W. J. Minkowycz, E. M. Sparrow, and J. Y. Murthy (Eds.), Handbook of Numerical Heat Transfer, 2nd ed., Wiley, New York, pp. 493-522, 2006.

19. C. P. Naveira-Cotta, R. M. Cotta, H. R. B. Orlande, and O. Fudym, Eigenfunction Expansions for Transient Diffusion in Heterogeneous Media, Int. J. Heat Mass Transf., vol. 52, pp. 50295039, 2009.

20. C. P. Naveira Cotta, H. R. B. Orlande, R. M. Cotta, and J. S. Nunes, Integral Transforms, Bayesian Inference, and Infrared Thermography in the Simultaneous Identification of Variable Thermal Conductivity and Diffusivity in Heterogeneous Media, 14th International Heat Transfer Conference, Washington, DC, August 7-13, 2010.

21. D. C. Knupp, C. P. Naveira Cotta, J. V. C. Ayres, H. R. B. Orlande, R. M. Cotta, ExperimentalTheoretical Analysis of a Transient Heat Conduction Setup via Infrared Thermography and Unified Integral Transforms, Int. Review Chem. Eng., vol. 2, pp. 736-747, 2010.

22. S. Wolfram, The Mathematica Book, version 5.2, Cambridge-Wolfram Media, 2005.

23. J. E. Mark, Physical Properties of Polymers Handbook, Part III: Thermodynamic Properties, Springer, New York, chaps. 9 and 10, 2007.

24. L. A. Sphaier, R. M. Cotta, C. P. Naveira-Cotta, J. N. N. Quaresma, The UNIT Algorithm for Solving One-Dimensional Convection-Diffusion Problems Via Integral Transforms, Int. Comm. Heat Mass Transf., vol. 38, pp. 565-571, 2011. 